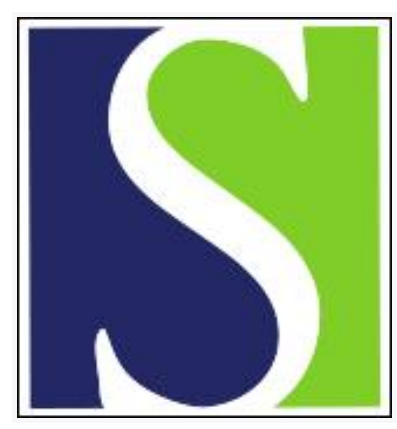

Scand J Work Environ Health 1978;4(2):122-130

https://doi.org/10.5271/sjweh.2715

Issue date: Jun 1978

Amount and distribution of welding fume lung contaminants among arc welders.

by Kalliomäki P-L, Alanko K, Korhonen O, Mattsson T, Vääränen V, Koponen M

Key terms: arc welder; lung; lung contaminant; lung contaminant distribution; lung retention; pulmonary clearance; shipyard arc welder; siderosis; welder; welding fume; welding fume lung contaminant

This article in PubMed: www.ncbi.nlm.nih.gov/pubmed/684387 


\title{
Amount and distribution of welding fume lung contaminants among arc welders
}

\author{
by PIRKKO-LIISA KALLIOMÄKI, M.D., L.Sc.(Eng.), ${ }^{1}$ KARI ALANKO, M.D., ${ }^{1}$ \\ OLLI KORHONEN, M.D.,1 TOR MATTSSON, M.D.,1 VESA \\ VAARANEN, M.D., ${ }^{1}$ and MATTI KOPONEN, M.Sc. ${ }^{2}$
}

\begin{abstract}
KALLIOMÄKI, P.-L., ALANKO, K., KORHONEN, O., MATTSSON, T., VAARANEN, V. and KOPONEN, M. Amount and distribution of welding fume lung contaminants among arc welders. Scand. $j$. work environ. \& health 4 (1978) 122-130. The amount and distribution of the welding fume lung contaminants was measured in 44 arc welders from two shipyards. The measurement was made from the determination of the permanent field after the subject was magnetized in a low external magnetic field, the values being used for the calculation of the amount of contaminants in the lungs. Less than $4 \mathrm{mg}$ of dust was found in the lungs of nonexposed controls. In the shipyard welder's lungs, after two years of exposure, on the average $7 \mathrm{mg}$ (range 4-15) of welding dust was observed. After a continuous exposure of about 18 years the amounts were $200 \mathrm{mg}$ (range $30-1,500$ ) in shipyard $A$ and $700 \mathrm{mg}(150-2,000)$ in shipyard B, respectively. On the basis of data obtained from retired welders, the clearance rate of $45 \%$ in welders from shipyard $A$ and $18 \%$ in shipyard $\mathrm{B}$ were calculated, the latter figure being probably more accurate. The distribution of contaminants was $52 \%$ in the right and $48 \%$ in the left lung. The radiological findings correlated well with the amounts of welding fume contaminants measured with the magnetic method.
\end{abstract}

Key words: lung contaminant distribution, lung retention, pulmonary clearance, shipyard arc welders, siderosis.

Quantitative measurement of welding fume lung contaminants has been difficult in vivo. Present methods as chest radiographs, lung function tests, and lung biopsies are either nonspecific or complicated for routine use.

The diagnosis of siderosis has been based on the radiological finding and a careful penetration of the history of exposure. Iron is an inert dust which does not induce fibrotic changes

1 Department of Occupational Medicine, Institute of Occupational Health, Helsinki, Finland.

2 Outokumpu Oy, Helsinki.

Reprint requests to: Dr. Olli Korhonen, Institute of Occupational Health, Haartmaninkatu 1, SF-00290 Helsinki 29, Finland. in the lungs. Siderosis is thus included among the benign pneumoconioses. However, other more active dusts and gaseous pollutants are inhaled simultaneously and may give rise to fibrotic lung lesions.

Cohen $(1,2)$ presented a method which is based on the measurement of remanent fields caused by welding fume magnetic particles. In a preliminary study (6) the lung contamination was measured in five arc welders.

In the present study the amount and distribution of welding fume lung contaminants were measured in different groups of arc welders, and the results were compared with radiological findings. Factors affecting the uptake (16) of welding fumes have also been discussed, as well as reasons for differences in the 
amount of lung contaminants between welders in the same type of welding work.

\section{MATERIAL AND METHODS}

\section{Subjects}

Several groups of welders, 44 altogether, and 10 controls were studied.

"Young" welders were vocational school students who had welded daily in workshops for about $4-5 \mathrm{~h}$ for one or two years.

Other welders were workers from two different shipyards, A and B. "Old" welders had welded continuously for at least ten years. Retired welders had not been exposed for at least ten months. Previously they had been working in the same shipyards (A and B) as the "old" welders for at least the last ten of their work years. One of the "old" welders died suddenly of a heart attack at home. His lungs were also studied post-mortem (table 1).

Controls were healthy subjects with no history or symptoms of such pulmonary diseases which might have influenced the measurements. They had never been exposed to welding fumes.

Further characteristics of the groups are given in table 1.

The mean length of retirement of the retired welders from shipyard A was 1.6 years. However, shortly before retirement many welders had stopped welding.
It was calculated that the mean "efficient" time of retirement was in fact 2.3 years in shipyard $\mathrm{A}$.

\section{Exposure}

The uptake of a given compound depends on several factors (16), e.g., body size, respiratory minute volume (work load), circulatory rate, concentration level, the physicochemical characteristics of the compound, duration of exposure, respirable fraction, and individual differences.

In arc welding, composition of the welding fumes depends upon the base material, electrode, and electrode coating. Welding fumes consist of gaseous and solid products. Gaseous components are mainly nitrogen oxides, carbon dioxide, carbon monoxide, fluorine compounds, and ozone.

In both shipyards ( $A$ and $B$ ) more than $80 \%$ of the electrodes used have been basic coated electrodes (Esab OK 48.00). The coating of this type of basic electrode contains calcspar $\left(\mathrm{CaCO}_{3}\right)$, fluorspar $\left(\mathrm{CaF}_{2}\right)$, ferrosilicon, iron powder, ferromanganese, and binding agents. The base metal has mostly been mild steel plates produced by Rautaruukki Oy, Finland.

The following elements have been detected in manual arc welding fumes: copper, fluorine, iron, manganese, magnesium, nickel, silicon, titanium and zinc. Chemical compounds present in welding fumes are not well known. However, the main components of welding fumes are

Table 1. Age, exposure time and the length of retirement of the study groups.

\begin{tabular}{|c|c|c|c|c|c|c|c|}
\hline \multirow[t]{2}{*}{ Group } & \multirow[t]{2}{*}{$\mathrm{N}$} & \multicolumn{2}{|c|}{$\begin{array}{c}\text { Age } \\
\text { (years) }\end{array}$} & \multicolumn{2}{|c|}{$\begin{array}{c}\text { Exposure time } \\
\text { (years) }\end{array}$} & \multicolumn{2}{|c|}{$\begin{array}{l}\text { Length of } \\
\text { retirement } \\
\text { (years) }\end{array}$} \\
\hline & & Mean & SD & Mean & SD & Mean & SD \\
\hline Controls & 10 & 30 & 5 & 0 & & 0 & \\
\hline "Young" welders & 10 & 16 & 1 & 2 & & 0 & \\
\hline \multicolumn{8}{|l|}{ Shipyard A } \\
\hline "Old" welders & 17 & 42 & 8 & 18 & 6 & 0 & \\
\hline Retired welders & 7 & 56 & 5 & 26 & 7 & 1.6 & 1.1 \\
\hline \multicolumn{8}{|l|}{ Shipyard B } \\
\hline "Old" welders & 5 & 42 & 4 & 18 & 4 & 0 & \\
\hline Retired welders & 5 & 68 & 4 & 30 & 3 & 7 & 4 \\
\hline Cadaver lung & 1 & 35 & & 11 & & 0 & \\
\hline
\end{tabular}


iron oxides (about 25-70\%), of which more than $90 \%$ is magnetite $\left(\mathrm{Fe}_{3} \mathrm{O}_{4}\right)(12$, 15).

The mass median diameter of fume particles is about $0.5 \mu \mathrm{m}$, and the count median is $0.05 \mu \mathrm{m}$ (12).

The fume concentration in the breathing zone of the welder depends on many factors, e.g., type of base material, type and dimensions of the electrodes, current, construction of the blocks to be welded, work location (confined space, open area), local ventilation, position of the welder.

Some examples of total particulate fume concentrations, expressed in milligrams per cubic meter and measured in the breathing zone of the welders in different work situations, are presented in table 2. They are based on surveys made by the Institute of Occupational Health, Helsinki (14).

No essential changes had occurred in the chemical composition of the electrodes which would have influenced the properties of the welding fumes. The steel to be welded did not contribute to any chemical change in the welding fumes during the past 25 years. The "old" and retired welders had had a homogeneous set of work conditions, e.g., ventilation, in each shipyard during the last $10-15$ years.

\section{Methods}

A clinical examination, including medical and occupational history and simple laboratory tests, was made. The standard questionnaire on respiratory symptoms of the Medical Research Council (9) was used. Spirometry was performed and the transfer factor was measured with the single breath method for carbon monoxide (3).

Chest radiographs in antero-posterior and lateral projections were taken on $350 \times 350 \mathrm{~mm}$ films. They were graded as follows: $0=$ normal; $1=$ fine mottling, localized in the central parts of the lungs only; 2 = more distinct mottling, involving more than the central parts of the lungs; and $3=$ generalized mottling, involving both lungs.

A panel of two radiologists and a specialist in lung diseases graded the radio-
Table 2. Examples of total particulate fume concentrations in the breathing zone of the welders during different work situations (mild steel and basic electrodes) (14).

\begin{tabular}{|c|c|}
\hline Welding situation & $\begin{array}{l}\text { Range of fume } \\
\text { concentration } \\
\left(\mathrm{mg} / \mathrm{m}^{3}\right)\end{array}$ \\
\hline $\begin{array}{l}\text { Welding shop, open space } \\
\text { Horizontal seam, welder on } \\
\text { his knees } \\
\text { Vertical seam } \\
\text { Inside of a block } \\
\text { Background sampling in } \\
\text { the shop }\end{array}$ & $\begin{array}{c}10-60 \\
5-10 \\
50-200 \\
2-10\end{array}$ \\
\hline $\begin{array}{l}\text { Ship } \\
\text { Confined space } \\
\text { Installation of a block, } \\
\text { open space } \\
\text { Installation of a block, } \\
\text { partly closed }\end{array}$ & $\begin{array}{l}100-400 \\
10-50 \\
50-200\end{array}$ \\
\hline
\end{tabular}

graphs without any information about the exposure of the subjects or clinical data. Four months after the first reading, the films were graded again by one of the radiologists. The results of the second reading agreed with the earlier ones.

Magnetic measurements were made of all the subjects once. In addition, five "old" welders from shipyard B were measured six times during one year.

The method of measuring the ferromagnetic pulmonary contamination has been described in detail earlier $(5,6)$. It is based on the permanent field of magnetized particles. First the thoracic area of the subject is magnetized in a low external magnetic field. Thereafter the permanent field caused by contaminants is measured with a SQUID type magnetometer on five transsectional planes of the thoracic region, both on the anterior and posterior sides (fig. 1).

The spatial resolution of the magnetometer was about $100 \mathrm{~mm}$. Thus the distribution of contaminants could be evaluated from the measured permanent magnetic field (PMF) curves. As a first approximation the half widths of the PMF curves, both in the transverse and longitudinal directions, represent the distribution. The half width is the distance between the two lateral points of the PMF curve where its height has reached half of the maximum value (fig. 1 ).

The results were expressed as values of the average magnetic field (AMF). They 

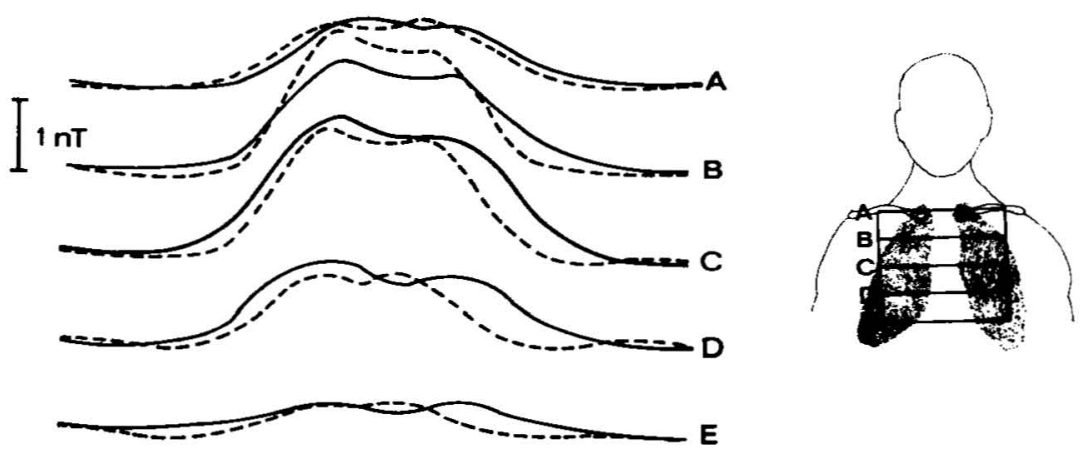

- Anterior side
---- Posterior side

Fig. 1. Permanent magnetic field curves measured on five transversal lines from a welder.

were converted to the corresponding magnetic moment which was further used in the calculation of the amount of welding fume contaminants in the lungs. The calibration, i.e., the relation between the measured magnetic moment and the amount of welding fume contaminants, was based on experimental studies of magnetic properties of welding fumes. Also the cadaver lung of the arc welder was used for calibration (5).

\section{RESULTS}

Anamnestic chronic bronchitis was observed in four of the 44 welders. One subject had mild and one moderate obstructive ventilatory impairment, whereas four had mild restrictive ventilatory impairment. An abnormally low transfer factor was observed in five subjects. The groups did not differ from each other on the basis of either anamnestic chronic bronchitis or lung function impairment. Of all the subjects, $60 \%$ smoked cigarettes. There were no significant differences in the smoking habits between the different groups.

No constant correlation was observed between the clinical and functional data on one hand and either radiological finding or the amount of the lung contaminants on the other.

Table 3. The measured average magnetic field $(\overline{\mathrm{B}}) 10 \mathrm{~min}$ after magnetization, the geometric standard deviation $(\delta \mathrm{g})$ and the approximate equivalent amount of welding dust for the different groups.

\begin{tabular}{|c|c|c|c|c|c|}
\hline \multirow{2}{*}{ Group } & \multirow{2}{*}{$\mathrm{N}$} & \multirow{2}{*}{$\begin{array}{c}\overline{\mathrm{B}} \\
\mathrm{nT}\end{array}$} & \multirow{2}{*}{$\delta \mathrm{g}$} & \multicolumn{2}{|c|}{$\begin{array}{l}\text { Approximate amount of welding } \\
\text { dust in the lungs (mg) }\end{array}$} \\
\hline & & & & Mean & Range \\
\hline Controls & 10 & 0.03 & - & $<4$ & - \\
\hline "Young" welders & 10 & 0.05 & 2 & 7 & $4-$ \\
\hline \multicolumn{6}{|l|}{ Shipyard A } \\
\hline "Old" welders & 17 & 1.5 & 3.5 & 200 & $30-1,500$ \\
\hline Retired welders & 7 & 0.83 & 1.7 & 110 & $40-250$ \\
\hline \multicolumn{6}{|l|}{ Shipyard B } \\
\hline "Old" welders & 5 & 4.9 & 3.0 & 700 & $150-2,000$ \\
\hline Retired welders & 5 & 1.5 & 2.3 & 200 & $60-500$ \\
\hline Cadaver lung & 1 & 0.74 & - & 100 & - \\
\hline
\end{tabular}




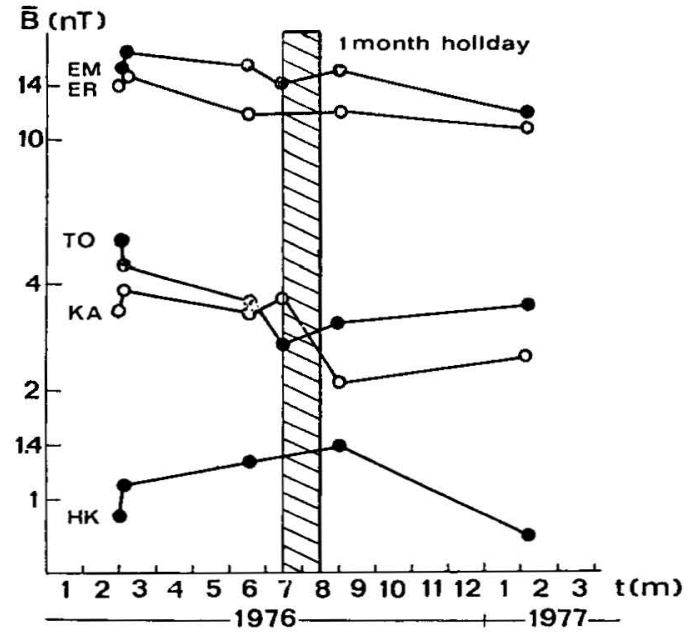

Fig. 2. Average permanent magnetic field $(\bar{B})$ as a function of time for five "old" welders from shipyard $B$.

\section{Amount of lung contaminants}

The average magnetic field $(\bar{B})$ and the equivalent amount of welding fume contaminants in different groups are presented in table 3 .

The values of the average magnetic field (the amount of lung contamination) differed greatly between individuals working under similar conditions. There was an almost significant difference $(p<0.05)$ between the lung contamination values of the workers in shipyards $\mathrm{A}$ and $\mathrm{B}$.

In the "old" and retired welders there was no correlation $\left(\mathrm{r}^{2}<0.02\right)$ between the measured average magnetic field, i.e., lung contamination and age or exposure time. The amount of retained lung contaminants was so small in the young welders that the measurement was difficult to perform. Thus the relative accuracy of the measurements was lower in this group. During the observation of one year, the young welders' second year of welding, the lung contamination did not increase.

When the average magnetic field of five "old" welders was measured six times during one year (fig. 2), a slight decrease, less than $10 \%$, in the amount of lung contamination was observed. The standard deviation of the successive results varied from 10 to $30 \%$, being lower at higher contamination levels.

\section{Clearance}

When it is assumed that retired and "old" welders have been similarly exposed, the clearance rate of lung contaminants can be estimated (13):

$$
\mathrm{k}=\frac{1}{\mathrm{~T}_{\mathrm{ret}}} \ln \frac{\overline{\mathrm{B}}_{\text {old }}}{\overline{\mathrm{B}}_{\text {retired }}},
$$

where $\mathrm{T}_{\text {ret }}=$ average length of retirement in groups of the retired welders and $\bar{B}=$ average magnetic field in groups of "old" and retired welders (table 3 ).

The clearance rate values were 45 and $18 \%$ per year for the retired welders in shipyards $\mathrm{A}$ and $\mathrm{B}$, respectively.

\section{Distribution}

The amounts of magnetic lung contamination on the anterior and posterior sides were not equal. This ratio varied from

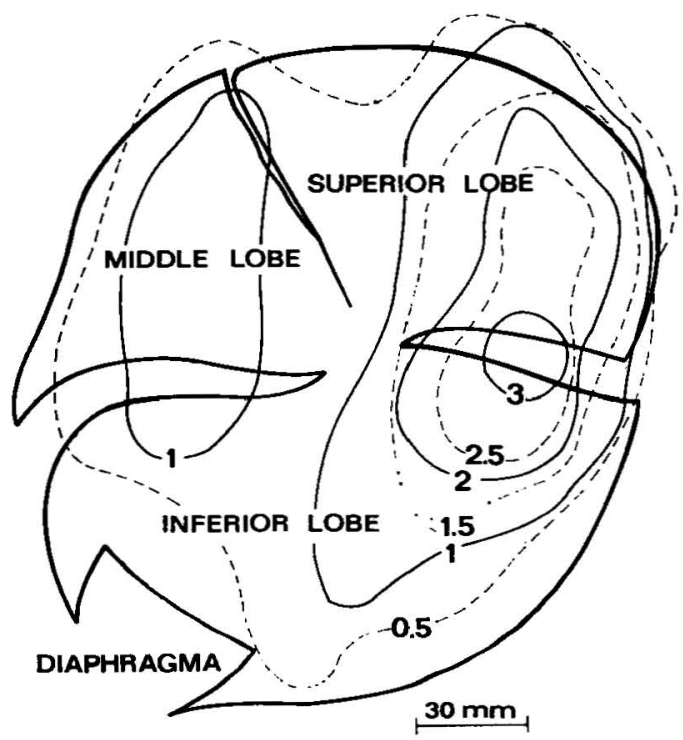

Fig. 3. Contour map of the measured permanent magnetic field of one slice from the right lung of a cadaver. The $10-\mathrm{mm}$ thick slice has been cut in the sagittal direction. The ventral side is to the left. Figures refer to nT units. 


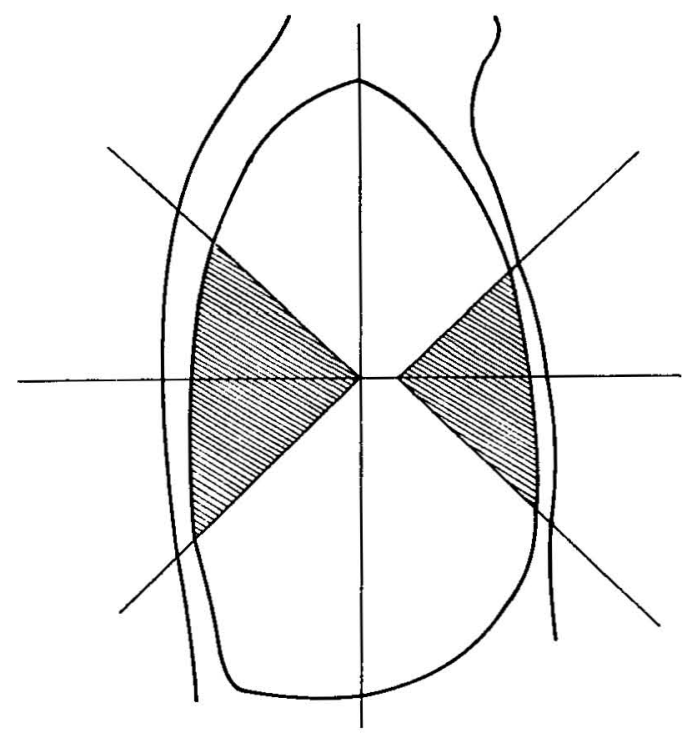

Fig. 4. Typical location of the centers of contaminated volumes on the sagittal plane.

0.5 to 2 , the standard deviation being \pm 0.3 and the mean value 1.0 . The result indicates that there is a high individual variation in antero-posterior distribution. Fig. 3 presents a typical contour map of the permanent magnetic field measured from one slice, cut from the right lung in the sagittal direction.

The mean \pm SD of the half-width values of the individual welders in the transverse direction was $220 \mathrm{~mm} \pm 20 \mathrm{~mm}$ on the anterior side and $230 \mathrm{~mm} \pm 10 \mathrm{~mm}$ on the posterior side, both in the "old" and in the retired welders.

The mean $\pm \mathrm{SD}$ values for the longitudinal half-width values were $150 \mathrm{~mm}$ 王 $23 \mathrm{~mm}$ (anterior) and $170 \mathrm{~mm} \pm 40 \mathrm{~mm}$ (posterior) for the "old" and $130 \mathrm{~mm} \pm$ $30 \mathrm{~mm}$ (anterior) and $150 \mathrm{~mm} \pm 20 \mathrm{~mm}$ (posterior) for the retired welders. The difference between the "old" and retired welders in the longitudinal distribution of contaminant particles was almost significant $(\mathrm{p}<0.05)$.

The contamination tended to be located in the shaded lung area in figs. 4 and 5.

The distribution of contamination between both lungs was $52 \%$ in the right and $48 \%$ in the left, the standard deviation being $\pm 6 \%$.

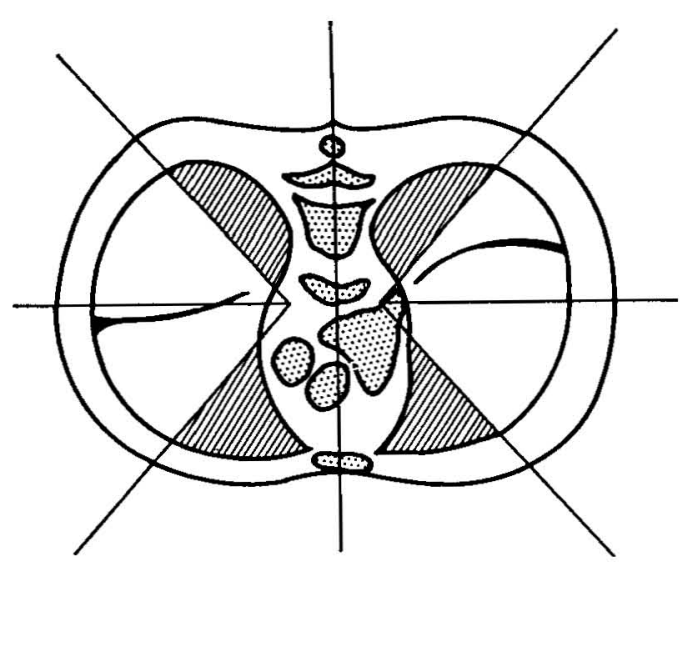

Fig. 5. Typical location of the centers of contaminated volumes on the transverse plane.

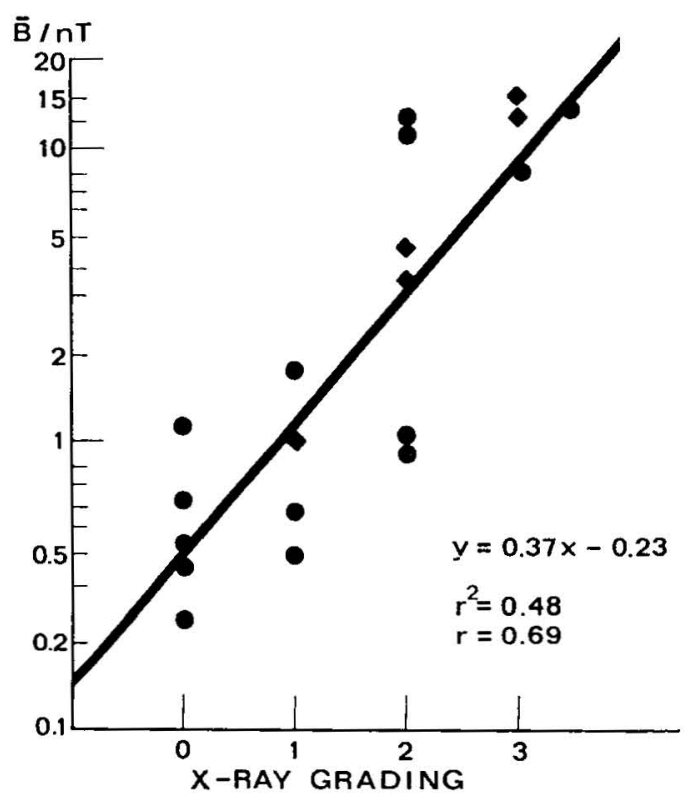

Fig. 6. Correlation between the logarithm of the average magnetic field $(\bar{B})$ and radiological findings of "old" welders from shipyard A (•) and shipyard B ( $\$$ ). (Radiological grading: $0=$ normal; 1 = fine mottling, localized in the central parts of the lungs only; $2=$ more distinct mottling, involving more than the central parts of the lungs; and $3=$ generalized mottling, involving both lungs) 


\section{Radiology}

The radiological finding in cases where lesions were seen consisted of micronodular lesions, which were generally more marked in the central parts of the lungs. This fine mottling occurred bilaterally. There was no blurring of the heart outline, nor any confluent opacities. The hilar shadows appeared prominent in some cases, but the hilar nodes were not enlarged. In these series regression of the lesions were not seen.

The correlation between the radiological findings and the average magnetic field is presented in fig. 6 .

A good correlation was obtained also between the radiological and magnetic mapping of contaminants in the slices of the cadaver lung.

\section{DISCUSSION}

The maximum amount of welding fume lung contaminants in arc welders was about $2 \mathrm{~g}$, the individual variation being high. In the "old" and retired welders, the amount of lung contamination was independent of exposure time. Thus, in these subjects too, balance between retention and clearance seemed to have been achieved, i.e., at least after the continuous exposure of 12 years. This assumption is supported by the stability of lung retention in the "old" welders during the observation period. The obtained maximum value depends on deposition rate, i.e., on the ambient concentration of respirable dust.

The clearance rates were 45 and $18 \%$ per year in shipyards $A$ and $B$, respectively. The smaller figure is probably more accurate due to the longer length of retirement. Based on the observation that the "effective" length of retirement was 2.3 years in shipyard $A$, the annual clearance would be $23 \%$ in the welders of that shipyard.

Due to clearance mechanisms, the amount of retained lung contaminants among welders reflects the exposure during the last 5-10 years. The average length of retirement was 1.6 years ("effective" retirement 2.3 years) in shipyard A and 7 years in shipyard B. The "old" and retired welders had had similar work conditions in both shipyards during the last 15-20 years, i.e., during the period determining the amount of retained contamination. Therefore the "old" and retired welders are comparable with each other.

If it is assumed that the welding fume concentration in air is $10 \mathrm{mg} / \mathrm{m}^{3}$, a welder's ventilation is $1 \mathrm{~m}^{3} / \mathrm{h}$ and the retained fraction of inhaled dust is $1 \%$ (slowly changing component), a clearance rate of $26 \%$ per year is reached for an average welder in shipyard B.

$\underline{10 \mathrm{mg} / \mathrm{m}^{3} \cdot \mathrm{lm}^{3} / \mathrm{h} \cdot 1800 \mathrm{~h} / \text { year } \cdot 1 \%}=26 \% /$ year

Even these coarse figures give a conception of the magnitude of clearance.

Differences in amount of lung contamination between the welders in shipyards A and B cannot be explained, for instance, with the measured fume concentrations shown in table 2 only. So far there are no results giving the real long-term mean exposure level to welding fumes in shipbuilding works. Also, e.g., personal habits with respect to work position and the use of respirators may cause great differences in the lung deposition of individuals, in spite of identical fume concentrations in the work space.

The base material and the electrodes were the same in both shipyards. All welders examined had worked in open welding shops as well as in the confined areas of ships. There are, however, some variations between shipyards $A$ and $B$ which may have influenced the different levels of exposure.

Shipyard A builds mainly tankers, and shipyard B ice breakers. Construction of these types of ships is quite different. Tankers consist of large spaces, while ice breakers contain many small compartments. Tankers are put together from pieces in the dry dock. Thus more of the welding work can be done in open areas, which is seldom possible in ice breakers. Due to the construction, the natural ventilation is better at welding points in tankers than in ice breakers. The exposure level in the welding shop of shipyard B may be higher than that of shipyard $A$ due to the more complex block constructions. Some general differences can also exist in the use of 
local ventilation and respiratory protective devices between the two shipyards.

Inhaled particles are carried by air flow into the lungs. Because of fast tracheobronchial clearance, it is primarily those particles retained at the alveolar level which are responsible for the contamination measured. At first glance contaminants seem to lodge in the areas of increased ventilation. Contamination distribution between the right and left lung coincides with that of ventilation (8). The longitudinal distribution of contamination in the lungs was slightly narrower than the ventilation area. In both longitudinal and transverse directions, the distribution of contaminants was narrower than suggested by lung dimensions and lung phantom models (5). One factor contributing to this narrowing effect is the difference in the length of bronchial trees. Long bronchial trees absorb more inhaled particles than short ones, and alveolar deposition is correspondingly decreased. On the other hand, ventilation occurs mainly in the central region of the lungs when the individual is involved in moderate physical activity. Therefore ventilation distribution could be responsible for the tendency of contaminants to deposit in the central areas of the lungs.

The cadaver lung study indicated that there were two concentration centers in each lung, one anterior and one posterior. In the cadaver lung, the contaminants tended to be located on the posterior side. In living subjects, both anterior and posterior contamination centers were observed, the quantity of contaminants varying with the individual.

It is the radio opacity of the inhaled iron particles that makes the changes visible on the radiographs. The location of the iron dust in the lungs is peribronchial, perivascular, and in the bronchopulmonary lymph nodes.

The changes seen on the radiographs have been described in different ways. Thus "reticulonodular shadowings" (7) "punctiform opacities" (4), and "discrete lung opacities" (10) have been used to describe the changes seen in the chest films. Less attention has been paid to siderosis than to, for instance, asbestosis and silicosis. The reason may be that siderotic changes are not considered to cause disability.

In cases where iron oxide alone has produced detectable radiological changes, they are usually very discrete, as in this series. The quality of the radiographs should be the best possible, which requires a good technigue. If mixed dust pneumoconiosis is produced, the interpretation is the most difficult and often siderotic changes cannot be indicated (definitely). Any lesions producing fibrotic changes tend to obscure the discrete nodular opacities produced by the iron dust. If fibrotic progression of the changes can be seen, there is some other component besides the inhaled iron. It has been pointed out (10) that iron oxide may influence the effects of free silica and cause lesions called "mixed dust fibrosis." In the present series a possible regression of the changes cannot yet be evaluated. The reversibility of the changes merits interest.

No correlation was found between symptoms or lung function impairment on one hand and radiological findings or the amount of welding fume contamination on the other. This observation is not surprising because the lung function parameters measured in this study reflect mainly either the properties of large airways or alveolocapillary membrane, as well as disturbances in the ventilationperfusion relationship. In connection with siderosis, pathological changes occurring in larger airways or the alveolocapillary membrane are probably secondary and due to, e.g., chronic bronchitis. Our findings are in agreement with those of others $(7,11)$.

No final conclusions can be made regarding the relationship between the amount of lung contaminants and health. First more extensive data and a followup study is necessary.

\section{ACKNOWLEDGMENT}

The authors wish to acknowledge Drs. J. Kataja, Valmet $\mathrm{Oy}$, and P. Ristola, Wärtsilä Oy, for their invaluable help in collecting the welders for the study. Mr. P. Holopainen provided his technical assistance. 


\section{REFERENCES}

1. COHEN, D. Ferromagnetic contamination in the lungs and other organ of the human body. Science 180 (1973) 745-748.

2. COHEN, D. Measurements of the magnetic fields produced by the human heart, brain and lungs. IEEE trans. mag. 11 (1975) 694700.

3. COTES, I. E. Lung function: Assessment and application in medicine (2nd ed.). Blackwell Scientific Publication, Oxford 1968. $619 \mathrm{p}$.

4. HAGLIND, O. Occupational health in the shipbuilding industry. In: Safety and health in shipbuilding and ship repairing. (Occupational safety and health series 27). International Labor Office, Geneva 1972, pp. 5-12.

5. KALLIOMÄKI, P.-L. Measurement of magnetic lung contamination in vivo: Evaluation of the method and its application to arc welders. (Doctoral dissertation). Helsinki, 1977. 60 p.

6. KALLIOMÄKI, P.-L., KARP, P., KATILA, T., MÄKIPÄA, P., SAAR, P. and TOSSAVAINEN, A. Magnetic measurements of pulmonary contamination. Scand. j. work environ. \& health 2 (1976) 232-239.

7. KLEINFELD, M., MESSITE, J., KOOYMAN, $O$. and SHAPIRO, J.' Welders' siderosis. Arch. environ. health 19 (1969) $70-73$.

8. KORHONEN, O. 133Xenon radiospirometry with moving detectors: Normal values and

Received for publication: 16 February 1978 repeatability. Scand. j. clin. lab. invest. 27 (1971) 113-122.

9. MEDICAL RESEARCH COUNCIL'S COMMITTEE ON THE AETIOLOGY OF CHRONIC BRONCHITIS. Standardized questionnaires on respiratory symptoms. Br. med. j. 2 (1960) 1665.

10. PARKES, W. R. Occupational lung disorders. Butterworth \& Co., Ltd., London 1974. $528 \mathrm{p}$.

11. SPACILOVA, M. and KAVAL, Z. Pulmonary $X$-ray and functional findings in electric-arc welders. Int. Arch. Arbeitsmed. 34 (1975) 232-236.

12. STERN, R. Production and characterization of a reference standard welding fume. Rapport SCV, The Danish Welding Institute, Copenhagen 1976. $66 \mathrm{p}$.

13. STÖBER, W., EINBRODT, J. and KLOSTERKÖTTER, W. Quantitative studies of dust retention in animal and human lungs after chronic inhalation. In: Inhaled particles and vapors II, Pergamon Press, Oxford 1965 , pp. $409-418$.

14. VIRTAMO, M. Hitsauksessa esiintyviä terveydellisiä haittatekijöitä. Hitsaustekniikka 1 (1973) 2-5.

15. VIRTAMO, M., TOSSAVAINEN, A. and RUISHALME, J. Valimoaineet (Työterveyslaitoksen tutkimuksia no. 109). Institute of Occupational Health, Helsinki 1975. 109 p.

16. WHO EXPERT COMMITTEE. Methods used in establishing permissible levels in occupational exposure to harmful agents (WHO tech. rep. ser. 601). World Health Organization, Geneva 1977. $68 \mathrm{p}$. 